\title{
Induration, itch, redness, and scaling of the left Auricle
}

\section{Erika Propst and Daisy Kopera* \\ Department of Dermatology, Centre of Aesthetic Medicine, Medical University Graz, Austria}

\section{Case report}

A 23-year old female patient presented with a 4-months history of an itchy left ear. Clinical examination revealed induration, confluent redness and scaling scattered over the left auricle. (Figure 1A) Previous treatments with various topical corticosteroids led to discrete temporal improvement only.

Based on the patient's presentation what is the most likely diagnosis?
A. eczema
B. sarcoidosis
C. lupus erythematosus

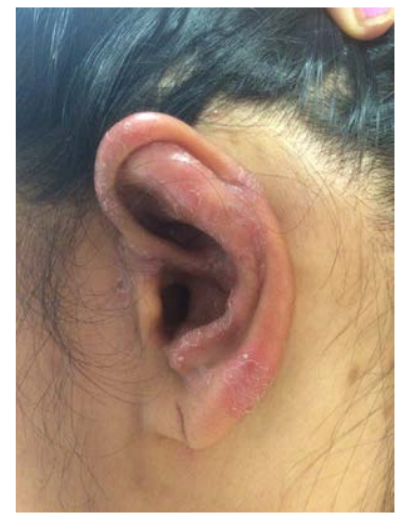

Figure 1A. Left auricle showing confluent redness and scaling.

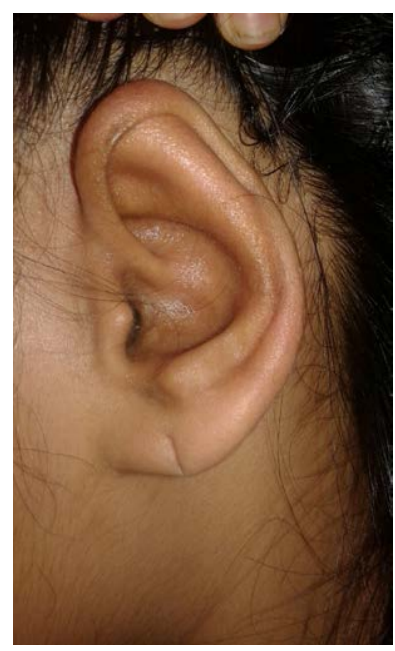

Figure 1B. Left auricle after topical treatment .

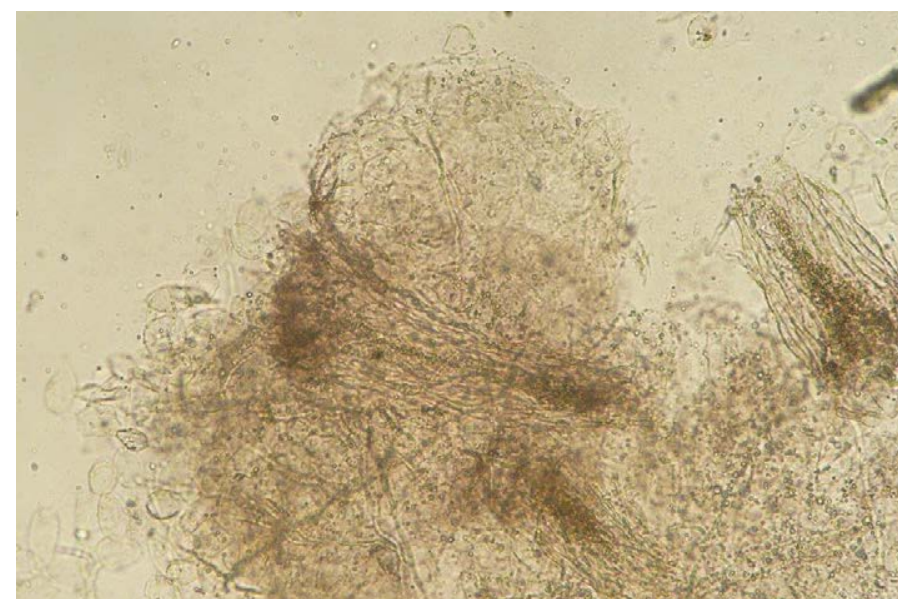

Figure 2. Native mycology revealing hyphen und spores.

D. fungal infection

E. perichondritis

By further interrogative investigation the patient admitted contact with a straying kitten.

Mycological tests presented hyphen and spores (microsporum canis) (Figure 2).

Topical treatment twice a day with miconazole for two weeks led to total remission of the fungal infection. (Figure 1B)

Diagnosis: superficial fungal infection (microsporum canis)

\section{Discussion}

Inflammatory lesions located on the auricle are relatively rare [1-3]. All differential diagnoses mentioned above have to be ruled out. Patient history has to be collated carefully and should include questioning on any contact to substances or animals. The appearance of fungal infections may have changed in the past and feature relatively mild clinical symptoms $[4,5]$. We therefore should be aware of ruling them out by non-invasive investigations (e.g. microbiological). Therefore they should be considered before biopsy and histopathology.

Notabene: Fungus omni presentis est! (fungus may occur anywhere).

Correspondence to: Daisy Kopera, Department of Dermatology, Centre of Aesthetic Medicine, Medical University Graz, Austria, E-mail: daisy.kopera@medunigraz.at

Received: March 04, 2017; Accepted: April 01, 2017; Published: April 04, 2017 


\section{References}

1. Sand M, Sand D, Brors D, Altmeyer P, Mann B, et al. (2008) Cutaneous lesions of the external ear. Head Face Med 4: 2. [Crossref]

2. Oztürkcan S, Oztürkcan S (2014) Dermatologic diseases of the external ear. Clin Dermatol 32: 141-152. [Crossref]
3. Kopera D, Soyer HP, Smolle J, Kerl H (2000) Pseudocyst of the auricle", othematoma and otoseroma: three faces of the same coin? Eur J Dermatol 10: 451-454. [Crossref]

4. Aly R (1994) Ecology and epidemiology of dermatophyte infections. J Am Acad Dermatol 31: S21-25. [Crossref]

5. Zhan P, Liu W (2017) The Changing Face of Dermatophytic Infections Worldwide Mycopathologia 182: 77. [Crossref]

Copyright: (C2017 Propst E. This is an open-access article distributed under the terms of the Creative Commons Attribution License, which permits unrestricted use, distribution, and reproduction in any medium, provided the original author and source are credited. 